\title{
Combination of primary tumor location and mismatch repair status guides adjuvant chemotherapy in stage II colon cancer
}

\author{
Lin Yang ${ }^{1,2,3, *}$, Wenzhuo $\mathrm{He}^{1,2,3, *}$, Qiong Yang ${ }^{4, *}$, Pengfei Kong ${ }^{1,2,3}$, Qiankun Xie ${ }^{1,2,3}$, \\ Chang Jiang ${ }^{1,2,3}$, Bei Zhang ${ }^{1,2,3}$ and Liang Ping $\mathbf{X i a}^{1,2,3}$ \\ ${ }^{1}$ Sun Yat-Sen University Cancer Center, Guangzhou, China \\ ${ }^{2}$ State Key Laboratory of Oncology in Southern China, Guangzhou, China \\ ${ }^{3}$ Collaborative Innovation Center for Cancer Medicine, Guangzhou, China \\ ${ }^{4}$ Sun Yat-Sen Memorial Hospital, Sun Yat-Sen University, Guangzhou, China \\ "These authors contributed equally to this work and share the first authorship
}

Correspondence to: Liang Ping Xia, email: xialp@sysucc.org.cn

Bei Zhang, email: zhangbei@sysucc.org.cn

Keywords: primary tumor location, mismatch repair, survival, adjuvant chemotherapy, colon cancer

Received: August 14, 2017

Accepted: September 22, 2017

Published: October 12, 2017

Copyright: Yang et al. This is an open-access article distributed under the terms of the Creative Commons Attribution License 3.0 (CC BY 3.0), which permits unrestricted use, distribution, and reproduction in any medium, provided the original author and source are credited.

\section{ABSTRACT}

Background: Current opinions on the benefits of adjuvant chemotherapy for stage II colon cancer are divided and reformative election of these patients is required. We examined whether the primary tumor location based on mismatch repair status and other risk factors could better inform the current guideline.

Materials and Methods: A total of 673 consecutive patients with stage II colon cancer were included in the analysis. Differences in the common clinicopathological factors between left-sided colon cancer and right-sided colon cancer were analyzed using Fisher's exact analysis. Kaplan-Meier analysis was used to distinguish the survival difference by primary tumor location and/or MMR status.

Results: RCC had a shorter overall survival $(P=0.001)$ and Disease-free survival $(P=0.050)$ than LCC but was associated with survival benefit from adjuvant chemotherapy ( $P=0.001$ and $P=0.011$ for OS and DFS, respectively). Mismatch repair-proficient had a shorter OS $(P=0.036)$ and disease free survival $(P=0.034)$ than mismatch-repair deficient but chemotherapy improved the OS $(P=0.007)$. When the primary tumor location and MMR status were combined, the PMMR/RCC was the only subgroup that could benefit from adjuvant chemotherapy $(P<0.001$ and $P=0.002$ for OS and DFS, respectively). Other tumors such as DMMR/RCC, DMMR/ LCC, and PMMR/LCC did not benefit.

Conclusions: The observed survival benefits in PMMR/RCC patients treated with adjuvant chemotherapy will allow better selection of patients for chemotherapy who are in stage II.

\section{INTRODUCTION}

It has been recently reported that colon cancer patients with stage III or high-risk stage II disease treated according to the National Comprehensive Cancer Network (NCCN) guidelines had survival benefit over those patients who received treatment that did not adhere to these guidelines [1]. Based on the NCCN guidelines https:// www.nccn.org/ [2], colon cancer patients with low-risk stage II disease can be enrolled in a clinical trial, observed without adjuvant therapy, or considered for capecitabine or 5-FU/leucovorin(LV). For patients with high-risk stage II disease, they can be considered for adjuvant chemotherapy with 5-FU/LV (5-Fluorouracil/Leucovorin), capecitabine, FOLFOX (5-Fluorouracil+oxaliplatin+Leucovorin) CapeOX (Oxaliplatin+Capecitabine), FLOX, or observation. It is a significant challenge to select the most precise option from the aforementioned diversity of choices when a patient with stage II disease presents to healthcare. Firstly, there are numerous risk factors, which are widely accepted as key factors 
impacting upon the decision to offer adjuvant chemotherapy, then the microsatellite status must also be taken into account. In patients with stage II disease, the medical consensus is that deficiency in mismatched repair protein expression (DMMR) or microsatellite stability high (MSI-H) tumor status are markers of a more favorable outcome and a predictor of decreased benefit (possible a detrimental impact) from adjuvant chemotherapy compared to floropyrimidine alone $[3,4]$. In contrast to the aforementioned findings, patients with stage II disease in the QUASAR study showed that although MMR was prognostic, it did not predict benefit or detrimental impact of chemotherapy [5]. A similar conclusion was also reached for patients with stage II disease that were treated with an irinotecan $+5-F U / L V$ (IFL) regimen [6]. The controversial results limit the value of MSI-H (microsatellite instability-high) in recommending adjuvant chemotherapy or not for patients with stage II disease. Several multigene assays have been developed in the hope of providing prognostic and predictive information in this unusual patient population. However, only the prognostic value has been confirmed $[7,8]$

The left and right colon are distinct at both the clinical and molecular level, giving rise to cancers, which have been treated as different diseased since 1990 [9]. Furthermore, the differing characteristics translate into a differential clinical outcome with right colorectal cancer (RCC) presenting a markedly poorer prognosis than left colorectal cancer (LCC) $[10,11]$. Recently, the primary tumor location was demonstrated to be predictive of treatment benefit from targeted therapy with antiEGFR and anti-VEGF agents in metastatic colorectal cancer (mCRC) $[12,13]$. This was especially true for cetuximab where survival benefit was only observed in LCC patients [14]. A similar phenomenon was observed for bevacizumab too. After generating a pooled analysis for stage II and III colon cancer patients, Gill [15] found that patients with high-risk resected colon cancer benefited from FU-based therapy only in RCC rather than in LCC. Nevertheless, primary tumor location has only recently been considered a predictor of treatment benefit in association with a limited number of targeted agents in mCRC. The evidence to date has not yet confirmed that primary tumor location can help the choice of adjuvant chemotherapy in patients with stage II disease alone, or combined with MMR status. Therefore, this is the main purpose of this study.

\section{MATERIALS AND METHODS}

We retrospectively studied a total of 673 eligible patients who received radical surgical resection for colorectal cancer treated at Sun Yat-sen University Cancer Center between October 2004 and March 2014. The inclusion criteria for the study were as follows: (i) pathological evidence of $\mathrm{CRC}$; (ii) complete baseline clinical information and laboratory data; (iii) clinical stage II according to the American Joint Commission on Cancer/International Union Against Cancer (AJCC/ UICC, the seventh version) and (iv) complete followup data. The exclusion criteria included (i) patients with rectal cancer; (ii) patients with ascertained MMR status; (iii) patients with more than one primary tumor that was concurrent; (iv) patients who died of non-cancer related diseased. Ethical approval was obtained from both institutions through the respective institutional review boards. The study protocol was designed in accordance with the guidelines outlined in the Declaration of Helsinki and was approved by the Ethics Committee of Sun Yat-sen University Cancer Center.

Colon cancers located in the cecum, ascending colon, and transverse colon were defined as RCC, while those located in the descending or sigmoid colon were defined as LCC [16-20]. Overall survival (OS) was defined as the time from the date of initial diagnosis to the date of death from cancer-related cause or until the date of the last follow-up. Disease-free survival (DFS) was ruled as the time from radical surgery time to the date diagnosed with the distant metastasis or relapse, death from cancerrelated cause, or until the date of the last follow-up. The median follow-up time was 111 months (range: 4-151 months) for OS and 105 months (range: 4-132 months) for DFS.

\section{Assessment of the CEA, CA199, and CRP}

All samples were collected before any treatment and were tested within $24 \mathrm{~h}$ after collection. The supernatants were processed for analysis of CEA and CA199 on a UniCelDxI 800 immunoassay system (Beckman Coulter, Brea, CA). Plasma CRP was measured using a high-sensitivity assay (Beckman Coulter, Woerden, the Netherlands) as previously described [21].

\section{MMR status determination}

The four most common mismatch repair proteins were assessed by immunohistochemistry using the standard Envision two-step procedure. Briefly, the slides were backed at $60^{\circ} \mathrm{C}$ for 2 hours, cleared through xylene, rehydrated, pre-treated with EDTA antigen retrieval buffer, treated in 3\% hydrogen for 20 min to prevent endogenous peroxidase activities, and then incubated with $10 \%$ normal goat serum at $37^{\circ} \mathrm{C}$ to block non-specific activity. Then, the slides were incubated at $4^{\circ} \mathrm{C}$ overnight using the following antibodies: MLH1 (1:50; Beijing Zhong Shan -Golden Bridge Biological Technology, Beijing, China), PMS2 (1:50; Beijing Zhong Shan -Golden Bridge Biological Technology, Beijing, China), MSH2 (1:50; Beijing Zhong Shan -Golden Bridge Biological Technology, Beijing, China) and MSH6 (1:50; Beijing Zhong Shan -Golden Bridge Biological Technology, Beijing, China). The tissues were incubated with a secondary antibody after washing 
(Envision; Dako, Glostrup, Denmark) for 1 hour at room temperature. Finally, the sections were systematically counterstained with $10 \%$ Mayer's hematoxylin, before dehydration and mounting in Crystal Mount. The known MMR-deficient colorectal carcinomas were observed as external negative controls and the non-neoplastic colonic mucosa, stromal cells, infiltrating lymphocytes or the centers of lymphoid follicles were regarded as internal positive controls. Immunostaining scores were recorded by two experienced pathologists and without prior knowledge of the patients' clinical data. Nuclear staining within tumor cells was defined as normal expression, while complete absence of nuclear staining within tumor cells with concurrent internal positive controls was considered to be negative protein expression. MLH1/PMS2/MSH2/ MSH6 protein expression negative cells were defined as tumors with loss of MLH1/PMS2/MSH2/MSH6 protein, visualized by light microscopy.

\section{Statistical analysis}

The continuous variables were transformed into dichotomous variables and the median value was used. The threshold of CEA and CA-199 were established at $5 \mathrm{ng} / \mathrm{ml}$ and $37 \mathrm{U} / \mathrm{ml}$ as commonly suggested [22]. Comparisons were performed using Fisher's exact test. The Kaplan-Meier method was used to calculate the OS and DFS survival curves, and the difference was evaluated using the log-rank test. Statistical analyses of survival data were performed using SPSS for Windows, version 19.0 (SPSS, Chicago, IL, USA). Two-sided $P$ values $<0.05$ were deemed significant. All data has been deposited at Sun Yat-sen University Cancer Center for future reference (RDD number: RDDA2017000269).

\section{RESULTS}

\section{Patient characteristics and survival}

A total of 673 patients with stage II CRC were enrolled, including 370 patients with LCC and 303 patients with RCC. At the end of the study period (March, 2017), 74 (11.0\%) patients had died because of cancer-related disease and 105 (15.6\%) patients had distant metastasis or recurrence. The 5-year OS rate for patients with LCC was $83.5 \%$ compared with $77.3 \%$ for patients with RCC $(P=0.001$, Figure 1A). There was also an apparently poorer DFS for those with RCC $(P=$ 0.050 , Figure 1B). The dMMR cohort also had improved survival compared with the pMMR cohort $(P=0.036$ and $P=0.034$ for OS and DFS, respectively, Figure 1C, 1D). The 5-year survival rate was $87 \%$ for the dMMR cohort, whereas it was merely $79.0 \%$ for the pMMR cohort. All common clinicopathologic features between RCC and LCC, and between dMMR and pMMR are shown in Table 1. Those with RCC tended to have higher CRP values
$(P<0.001)$, lower ALB $(P<0.001)$, adenocarcinoma, $(P<0.001)$, pMMR $(P<0.001)$, and TLN $>12(P<$ $0.001)$. Furthermore, the pMMR cohort was older $(P$ $=0.032)$, had higher CR $P$ values $(P<0.001)$, higher ALB (albumin) $(P=0.005)$, non-adenocarcinoma $(P=0.010)$, advanced stage cancer $(P=0.004)$, had RCC primary tumors $(P<0.001)$, TLN (Total lymph node) $>12$ $(P<0.001)$, vascular invasion $(P=0.030)$, and had been treated with chemotherapy $(P=0.001)$.

\section{The adjuvant chemotherapy benefit with primary tumor location}

The chemotherapy benefit was observed in the RCC cohort $(P=0.001$ and $P=0.011$ for OS and DFS, respectively, Figure 2A, 2B). However, it was not observed in the LCC cohort $(P=0.918$ and $P=0.894$ for OS and DFS, respectively; Figure 2C, 2D). Those with LCC had apparently better survival than the RCC cohort in the non-chemotherapy group $(P<0.001$ and $P=0.009$ for OS and DFS, respectively; Figure 2E, 2F). The improved LCC survival benefit over the RCC cohort disappeared in the chemotherapy group $(P=0.858$ and $P=0.587$ for OS and DFS, respectively; Figure 2G, $2 \mathrm{H}$ ).

\section{The adjuvant chemotherapy benefit with mismatch repair status}

The pMMR cohort had an improved OS rather than improved DFS if they received adjuvant chemotherapy $(P=0.007$ and $P=0.075$ for OS and DFS, respectively; Figure 3A, 3B). The dMMR cohort that received adjuvant chemotherapy did not attain survival benefit $(P=0.143$ and $P=0.187$ for OS and DFS, respectively; Figure 3C, 3D). As expected, in the non-chemotherapy cohort, the dMMR cohort had a better prognosis than the pMMR cohort for OS $(P=0.045$, Figure $3 \mathrm{E})$ but a significant difference in DFS was not observed $(P=0.064$, Figure $3 F)$ while the difference narrowed even further after chemotherapy $(P=0.136$ and $P=0.129$, respectively; Figure $3 \mathrm{G}$ and $3 \mathrm{H})$.

\section{The combination of the MMR/primary tumor location survival analysis}

We classified CRCs into four groups based on MMR status and primary tumor location: pMMR /RCC, dMMR /RCC, pMMR /LCC, and dMMR /LCC. We looked at both the whole cohort and the non-chemotherapy cohort, and compared the pMMR /RCC cancers. We found that the dMMR /RCC, dMMR /LCC, and pMMR /LCC cases exhibited significantly better outcomes $(P<0.001$ and $P$ $<0.001$ for OS, $P=0.002$ and $P<0.001$ for DFS, Figure $4 \mathrm{~A}-4 \mathrm{D})$. The survival differences disappeared in the chemotherapy cohort $(P=0.522$ and $P=0.442$ for OS and DFS, respectively; Figure 4E, 4F). The pMMR/RCC 
cohort gained significant benefit with chemotherapy $(P<$ 0.001 and $P=0.002$ for OS and DFS, respectively; Figure 5A, 5B), whereas pMMR/LCC, dMMR/RCC, dMMR/ LCC or other subgroups derived no benefit $(P=0.705$, $P=0.381$ and $P=0.169$ for $\mathrm{OS} ; P=0.610, P=0.232$ and $P=0.211$ for DFS, respectively; Figure $5 \mathrm{C}-5 \mathrm{H})$.

We analyzed the distribution of different chemotherapeutic regimens in the four subgroups, as shown in Table 2 but these were not significantly different $(P=0.986) .430$ patients without adjuvant chemotherapy and 243 patients were recommended to follow the 5-FUbased adjuvant-chemotherapy regimens. This included 1 patient with 5-Fu/LV, 98 patients with Xeloda, 136 patients with XELOX, and 8 patients with FOLFOX.

Furthermore, we compared the number of risk factors, MMR status, TLN number, T stage, vascular invasion, nerve invasion, intestinal obstruction, and intestinal perforation, between the chemotherapy cohorts and non-chemotherapy cohort for the four groups. As shown in Table 3, the number of risk factors balanced across all groups $(P=0.250, P=0.684, P=0.547$, and $P$ $=0.530$, respectively; Table 3 ).

Additionally, in the $\mathrm{pMMR} / \mathrm{RCC}$ subgroup receiving adjuvant chemotherapy, there was no survival difference between the cohorts with or without the risk factors $(P=$ 0.756 for OS and $P=0.478$ for DFS, Figure 6). Similar results were found in the $\mathrm{pMMR} / \mathrm{RCC}$ subgroup without
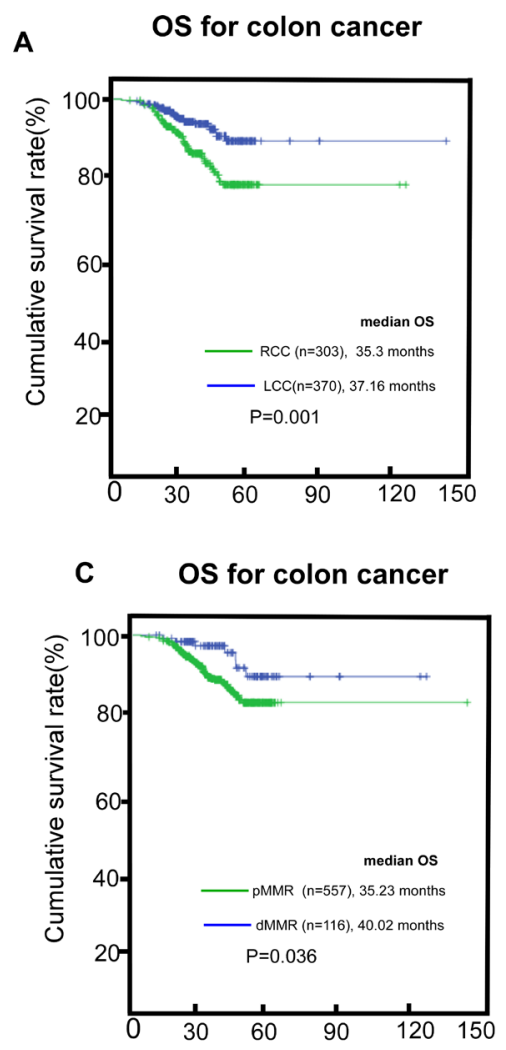

adjuvant chemotherapy $(P=0.847$ for $\mathrm{OS}$ and $P=0.528$ for DFS, Figure 6).

\section{DISCUSSION}

In mCRC [12, 23] or CRC without distinguished stages [24], the primary tumor location is a prognostic factor that suggests those with LCC have a significantly longer OS than RCC. However, its prognostic value has not been fully studied in these early studies. Our results showed that those with LCC had survival advantages compared with RCC patients, and that these were evident for stage II disease too. Similar findings in our previous study exploring mCRC were also noted [25]. Both OS and DFS advantages associated with LCC were not only evident for all stage II disease but also existed in patients without chemotherapy, which excluded the influence of treatment interventions. It is also worth noting that the common prognostic clinicopathological features were very similar between LCC and RCC patients. These data strongly support the poor prognosis of RCC in stage II disease. The same comparison was conducted in dMMR and pMMR, where the results showed that those with dMMR had a much longer OS than pMMR, which is in accordance with other studies [26, 27].

The role of MMR status guiding adjuvant chemotherapy in stage II CRC was studied, and the
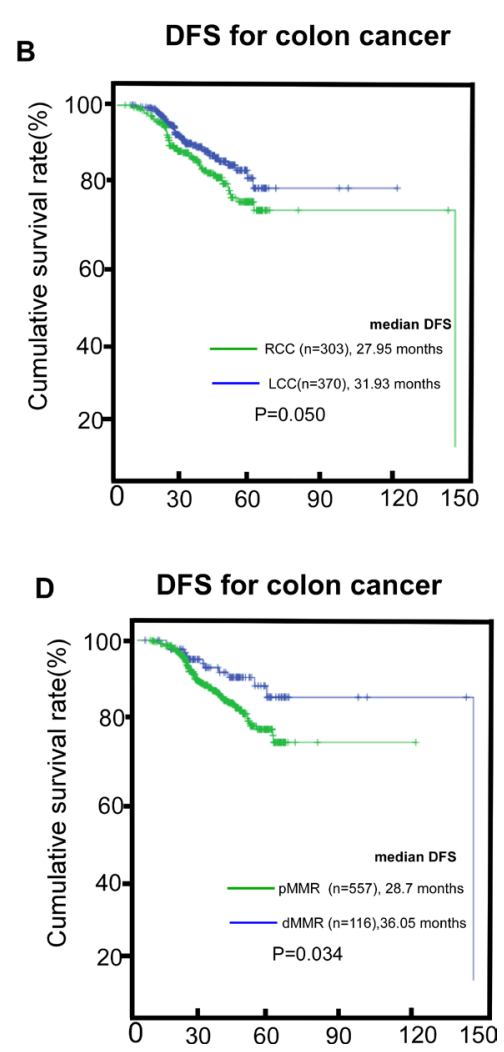

Figure 1: The survival (OS, overall survival; DFS, disease-free survival) difference in RCC (right-sided colon cancer) and LCC (left-sided colon cancer) in the whole cohort, (A and $\mathbf{B})$ the survival difference between the dMMR (mismatch-repair deficient) cohort and the pMMR (mismatch-repair proficient) cohort, $(\mathbf{C}$ and $\mathbf{D})$. 
Table 1: The clinicopathogical characteristics of RCC and LCC groups, and dMMR and pMMR groups

\begin{tabular}{|c|c|c|c|c|c|c|c|}
\hline Characteristics & $\begin{array}{c}\text { All, Number } \\
(\%)\end{array}$ & $\begin{array}{c}\text { LCC, } \\
\text { Number }(\%)\end{array}$ & $\begin{array}{c}\text { RCC, Number } \\
(\%)\end{array}$ & $P$ & $\begin{array}{c}\text { dMMR, } \\
\text { Number }(\%)\end{array}$ & $\begin{array}{c}\text { pMMR, } \\
\text { Number }(\%)\end{array}$ & $P$ \\
\hline Age, years & & & & 0.080 & & & 0.032 \\
\hline$<59$ & $357(53.0 \%)$ & $185(51.8 \%)$ & $172(48.2 \%)$ & & $72(20.2 \%)$ & $285(79.8 \%)$ & \\
\hline$\geq 59$ & $316(47.0 \%)$ & $185(58.5 \%)$ & $131(41.5 \%)$ & & $44(13.9 \%)$ & $272(86.1 \%)$ & \\
\hline Sex & & & & 0.077 & & & 0.076 \\
\hline Male & $409(60.8 \%)$ & $236(57.7 \%)$ & $173(42.3 \%)$ & & $62(15.2 \%)$ & $347(84.8 \%)$ & \\
\hline Female & $264(39.2 \%)$ & $134(50.8 \%)$ & $130(49.2 \%)$ & & $54(20.5 \%)$ & $210(79.5 \%)$ & \\
\hline CRP, mg/L & & & & $<0.001$ & & & $<0.001$ \\
\hline$<3.26$ & $333(49.5 \%)$ & $210(63.1 \%)$ & $123(36.9 \%)$ & & $36(10.8 \%)$ & $297(89.2 \%)$ & \\
\hline$\geq 3.26$ & $340(50.5 \%)$ & $160(47.1 \%)$ & $180(52.9 \%)$ & & $80(23.5 \%)$ & $260(76.5 \%)$ & \\
\hline ALB, g/L & & & & $<0.001$ & & & 0.005 \\
\hline$<40.2$ & $367(54.5 \%)$ & $177(48.2 \%)$ & $190(51.8 \%)$ & & $77(21.0 \%)$ & $290(79.0 \%)$ & \\
\hline$\geq 40.2$ & $306(45.5 \%)$ & $193(63.1 \%)$ & $113(36.9 \%)$ & & $39(12.7 \%)$ & $267(87.3 \%)$ & \\
\hline CEA, ng/mL & & & & 0.204 & & & 0.276 \\
\hline$<5$ & $447(66.4 \%)$ & $238(53.2 \%)$ & $209(46.8 \%)$ & & $72(16.1 \%)$ & $375(83.9 \%)$ & \\
\hline$\geq 5$ & $226(33.6 \%)$ & $132(58.4 \%)$ & $94(41.6 \%)$ & & $44(19.5 \%)$ & $182(80.5 \%)$ & \\
\hline CA199, U/mL & & & & 0.394 & & & 0.235 \\
\hline$<37$ & $575(85.4 \%)$ & $320(55.7 \%)$ & $255(44.3 \%)$ & & $95(16.5 \%)$ & $480(83.5 \%)$ & \\
\hline$\geq 37$ & $98(14.6 \%)$ & $50(51.0 \%)$ & $48(49.0 \%)$ & & $21(21.4 \%)$ & $77(78.6 \%)$ & \\
\hline Pathology & & & & $<0.001$ & & & 0.010 \\
\hline Adenocarcinoma & $579(86.0 \%)$ & $340(58.7 \%)$ & $239(41.3 \%)$ & & $25(26.6 \%)$ & $69(73.4 \%)$ & \\
\hline $\begin{array}{l}\text { Mucinous or } \\
\text { signet-ring cell }\end{array}$ & $94(14.05)$ & $30(31.9 \%)$ & $64(68.1 \%)$ & & $91(15.7 \%)$ & $488(84.3 \%)$ & \\
\hline Tumor location & & & & & & & $<0.001$ \\
\hline $\mathrm{LCC}$ & $370(55.0 \%)$ & & & & $36(9.7 \%)$ & $334(90.3 \%)$ & \\
\hline $\mathrm{RCC}$ & $303(44.9 \%)$ & & & & $80(26.4 \%)$ & $223(73.6 \%)$ & \\
\hline MMR & & & & $<0.001$ & & & \\
\hline dMMR & $116(17.2 \%)$ & $36(31.0 \%)$ & $80(69.0 \%)$ & & & & \\
\hline pMMR & $557(82.8 \%)$ & $334(60.0 \%)$ & $223(73.6 \%)$ & & & & \\
\hline T stage & & & & 0.350 & & & 0.004 \\
\hline IIa & $539(80.1 \%)$ & $302(56.0 \%)$ & $237(44.0 \%)$ & & $81(15.0 \%)$ & $458(85.0 \%)$ & \\
\hline $\mathrm{IIb}$ & $106(15.8 \%)$ & $56(52.8 \%)$ & $50(47.2 \%)$ & & $30(28.3 \%)$ & $76(71.7 \%)$ & \\
\hline IIc & $28(4.2 \%)$ & $12(42.9 \%)$ & $16(57.1 \%)$ & & $5(17.9 \%)$ & $23(82.1 \%)$ & \\
\hline TLN & & & & $<0.001$ & & & 0.014 \\
\hline$<12$ & $247(36.7 \%)$ & $184(74.5 \%)$ & $63(25.5 \%)$ & & $31(12.6 \%)$ & $216(87.4 \%)$ & \\
\hline$\geq 12$ & $426(63.3 \%)$ & $186(43.7 \%)$ & $240(56.3 \%)$ & & $85(20.0 \%)$ & $341(80.0 \%)$ & \\
\hline $\begin{array}{l}\text { Vascular } \\
\text { invasion }\end{array}$ & & & & 0.437 & & & 0.030 \\
\hline No & $585(86.9 \%)$ & $325(55.6 \%)$ & $260(44.4 \%)$ & & $108(18.5 \%)$ & $477(81.5 \%)$ & \\
\hline Yes & $88(13.1 \%)$ & $45(51.1 \%)$ & $43(48.9 \%)$ & & $8(9.1 \%)$ & $80(90.9 \%) \%)$ & \\
\hline Nerve invasion & & & & 0.667 & & & 0.194 \\
\hline No & $665(98.8)$ & $365(54.9 \%)$ & $300(45.1 \%)$ & & $116(17.4 \%)$ & $549(82.6 \%)$ & \\
\hline Yes & $8(1.2 \%)$ & $5(62.5 \%)$ & $3(37.5 \%)$ & & $0(0.0 \%)$ & $8(100.0 \%)$ & \\
\hline $\begin{array}{l}\text { Intestinal } \\
\text { obstruction }\end{array}$ & & & & 0.284 & & & 0.262 \\
\hline
\end{tabular}




\begin{tabular}{|c|c|c|c|c|c|c|c|}
\hline No & $667(99.1 \%)$ & $368(55.2 \%)$ & $299(44.8 \%)$ & & $116(17.4 \%)$ & $551(82.6 \%)$ & \\
\hline Yes & $6(0.9 \%)$ & $2(33.3 \%)$ & $4(66.7 \%)$ & & $0(0.0 \%)$ & $6(100.0 \%)$ & \\
\hline Chemotherapy & & & & 0.477 & & & 0.001 \\
\hline Yes & $243(36.1 \%)$ & $138(56.8 \%)$ & $105(43.2 \%)$ & & $26(10.7 \%)$ & $217(89.3 \%)$ & \\
\hline No & $430(63.9 \%)$ & $232(54.0 \%)$ & $198(46.0 \%)$ & & $90(20.9 \%)$ & $340(79.1 \%)$ & \\
\hline Survival status & & & & $<0.001$ & & & 0.060 \\
\hline Live & $599(89.0 \%)$ & $345(57.6 \%)$ & $254(42.4 \%)$ & & $109(18.2 \%)$ & $490(81.8 \%)$ & \\
\hline Dead & $74(11.0 \%)$ & $25(33.8 \%)$ & $49(66.2 \%)$ & & $7(9.5 \%)$ & 67 (90.5\%) & \\
\hline $\begin{array}{l}\text { Distant } \\
\text { metastasis or } \\
\text { relapse }\end{array}$ & & & & 0.007 & & & 0.152 \\
\hline Yes & $105(15.6 \%)$ & $45(42.9 \%)$ & $60(57.1 \%)$ & & $13(12.4 \%)$ & $92(87.6 \%)$ & \\
\hline No & $568(84.4 \%)$ & $325(57.2 \%)$ & $243(42.8 \%)$ & & $103(18.1 \%)$ & $465(81.9 \%)$ & \\
\hline
\end{tabular}

Abbreviations: CRC, colon cancer; LCC, Left-sided colon cancer; RCC, right-sided colon cancer; CRP, C-reactive protein; WBCs, white blood cells; ALB, albumin; CA199, Carbohydrate Antigen 19-9; CEA, Carcinoembryonic antigen; MMR, Mismatch repair; dMMR, mismatch-repair deficient; pMMR, mismatch-repair proficient; TLN, Total lymph node cleared in surgery.

Table 2: The distribution of chemotherapeutic regimens among the four subgroups after combining primary tumor location and mismatch repair status

\begin{tabular}{lcccc}
\hline Characteristics & $\begin{array}{c}\text { All, Number } \\
(\%)\end{array}$ & $\begin{array}{c}\text { Single-chemotherapy, } \\
\text { Number (\%) }\end{array}$ & $\begin{array}{c}\text { Combined-chemotherapy, } \\
\text { Number (\%) }\end{array}$ & $P$ \\
\hline $\begin{array}{l}\text { MMR status/primary } \\
\text { tumor location }\end{array}$ & & & & 0.986 \\
dMMR/LCC & $14(4.7 \%)$ & $4(28.6 \%)$ & $10(71.4 \%)$ & \\
pMMR/LCC & $158(53.0 \%)$ & $53(33.5 \%)$ & $105(66.5 \%)$ & \\
dMMR/RCC & $21(7.0 \%)$ & $7(33.3 \%)$ & $14(66.7 \%)$ \\
pMMR/RCC & $105(35.2 \%)$ & $35(33.3 \%)$ & $70(66.7 \%)$ & \\
\hline
\end{tabular}

Abbreviations: dMMR/LCC, mismatch-repair deficient/left-sided colon cancer; pMMR/LCC, mismatch-repair proficient/ left-sided colon cancer; dMMR/RCC, mismatch-repair deficient/right-sided colon cancer; pMMR/RCC, mismatch-repair proficient/right-sided colon cancer.

Table 3: The distribution of the number of risk factors after combining primary tumor location and mismatch repair status among the four subgroups respectively

\begin{tabular}{|c|c|c|c|c|}
\hline Characteristics & $\begin{array}{c}\text { All, } \\
\text { Number (\%) }\end{array}$ & $\begin{array}{c}\text { Non-chemotherapy, Number } \\
(\%)\end{array}$ & $\begin{array}{c}\text { With chemotherapy, Number } \\
(\%)\end{array}$ & $P$ \\
\hline \multicolumn{5}{|l|}{$\mathrm{dMMR} / \mathrm{LCC}^{*}$} \\
\hline The number of risk factors & & & & 0.250 \\
\hline 0 & $12(33.3 \%)$ & $4(33.3 \%)$ & $8(66.7 \%)$ & \\
\hline 1 & $18(50.0 \%)$ & $3(16.7 \%)$ & $15(83.3 \%)$ & \\
\hline 2 & $6(16.7 \%)$ & $3(50.0 \%)$ & $3(50.0 \%)$ & \\
\hline \multicolumn{5}{|l|}{$\mathrm{pMMR} / \mathrm{LCC}^{* *}$} \\
\hline The number of risk factors & & & & 0.684 \\
\hline 0 & $114(34.1 \%)$ & $74(64.9 \%)$ & $40(35.1 \%)$ & \\
\hline 1 & $169(50.6 \%)$ & $102(60.4 \%)$ & $67(39.6 \%)$ & \\
\hline 2 & $47(14.1 \%)$ & $32(68.1 \%)$ & $15(31.9 \%)$ & \\
\hline 3 & $4(1.2 \%)$ & $2(50.0 \%)$ & $2(50.0 \%)$ & \\
\hline \multicolumn{5}{|l|}{$\mathrm{dMMR} / \mathrm{RCC}^{* * *}$} \\
\hline The number of risk factors & & & & 0.547 \\
\hline 0 & $9(11.3 \%)$ & $8(88.9 \%)$ & $1(11.1 \%)$ & \\
\hline 1 & $45(56.3 \%)$ & $36(80.0 \%)$ & $9(20.0 \%)$ & \\
\hline 2 & $25(31.3 \%)$ & $23(92.0 \%)$ & $2(8.0 \%)$ & \\
\hline
\end{tabular}


3

pMMR/ RCC $C^{* * * *}$

The number of risk factors

0

1

2

3

$1(1.3 \%)$

$1(100.0 \%)$

Abbreviations: dMMR/LCC, mismatch-repair deficient/left-sided colon cancer; $\mathrm{pMMR/LCC,} \mathrm{mismatch-repair} \mathrm{proficient/left-sided} \mathrm{colon} \mathrm{cancer;} \mathrm{dMMR/}$ $\mathrm{RCC}$, mismatch-repair deficient/right-sided colon cancer; pMMR/RCC, mismatch-repair proficient/right-sided colon cancer.

A

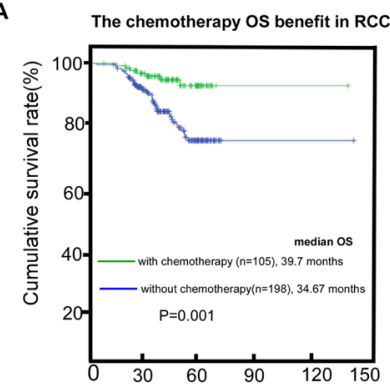

C

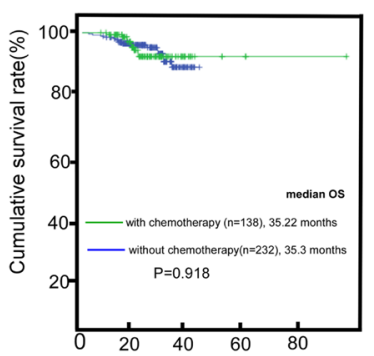

The OS difference for RCC and LCC in

E the cohort without chemotherapy

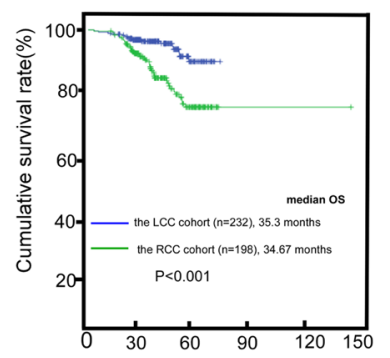

The OS difference for RCC and LCC in

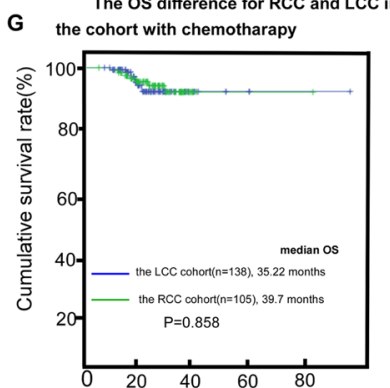

B

$\begin{array}{cc}19(65.5 \%) & 10(34.5 \%) \\ 75(55.6 \%) & 60(44.4 \%) \\ 34(63.0 \%) & 20(37.0 \%) \\ 2(40.0 \%) & 3(60.0 \%)\end{array}$
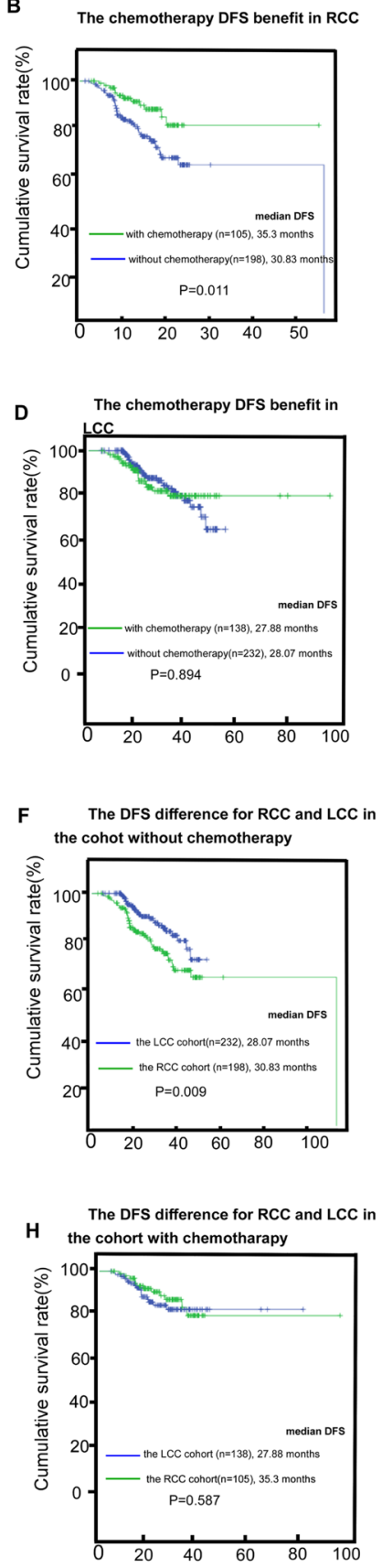

Figure 2: The chemotherapy benefit in RCC (right-sided colon cancer) and LCC (left-sided colon cancer) for OS (overall survival) and DFS (disease-free survival), (A-D) the survival (OS and DFS) difference between RCC and LCC in the subgroups without adjuvantchemotherapy or with adjuvant-chemotherapy, $(\mathbf{E}-\mathbf{H})$. 
A The chemotherapy OS benefit in pMMR Cohort

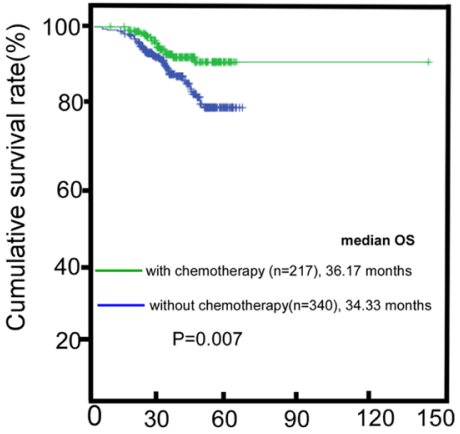

C The chemotherapy OS benefit in dMMR Cohort

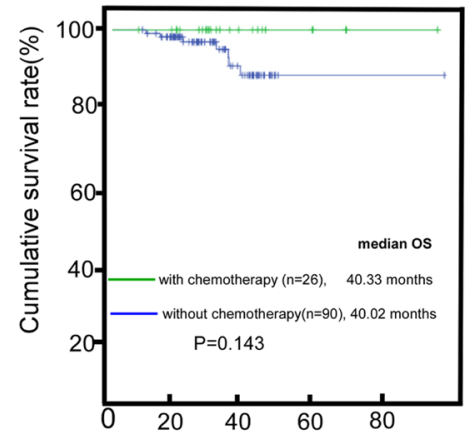

E

The OS difference for dMMR and
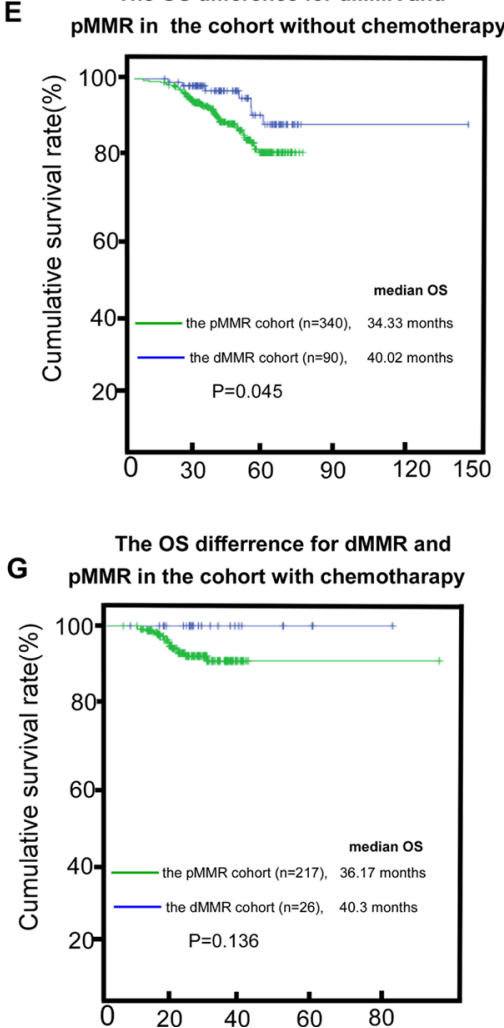

B

The chemotherapy DFS benefit in pMMR Cohort

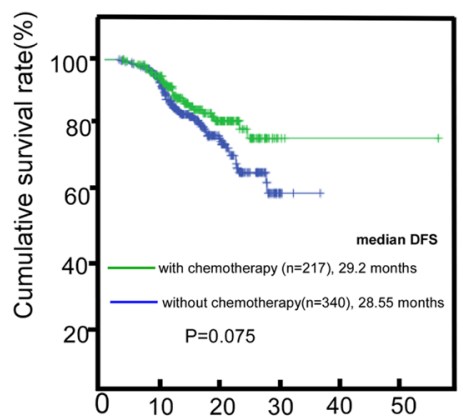

D The chemotherapy DFS benefit in AMMR Cohort

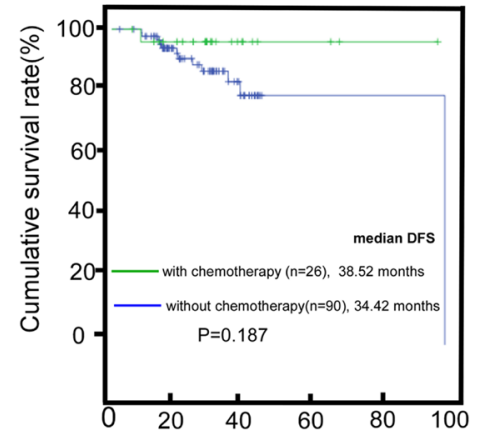

F The DFS difference for dMMR and pMMR in the cohot without chemotherapy

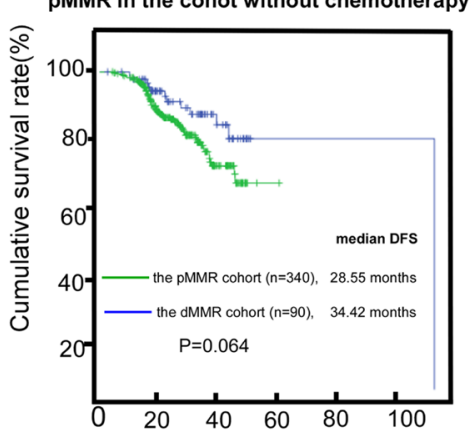

H The DFS differrence for MSS and MSIS

$\mathrm{H}$ in the cohort with chemotharapy

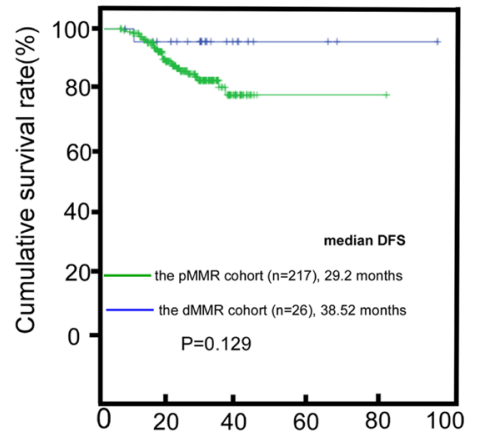

Figure 3: The chemotherapy benefit in the dMMR (mismatch-repair deficient) and the pMMR (mismatch-repair proficient) for OS (overall survival) and DFS (disease-free survival), (A-D); the survival (OS and DFS) difference between dMMR and pMMR in the subgroups without adjuvant-chemotherapy or with adjuvant-chemotherapy, $(\mathbf{E}-\mathbf{H})$. 
results accord with references that suggest MSI patients are unable to obtain survival benefit from chemotherapy [26]. The primary tumor location as a predictor of targeted agents in $\mathrm{mCRC}$ has been fully explored in recent years and showed that cetuximab survival benefit was limited to LCC patients $[13,28-30]$. However, while the majority of studies found that only LCC patients gained survival advantages from bevacizumab [12, 25, 31], some studies found that those $\mathrm{CRC}$ in both sides can get survival benefit, although LCC gained more [32]. Nevertheless,

A The OS difference in the four subgroups

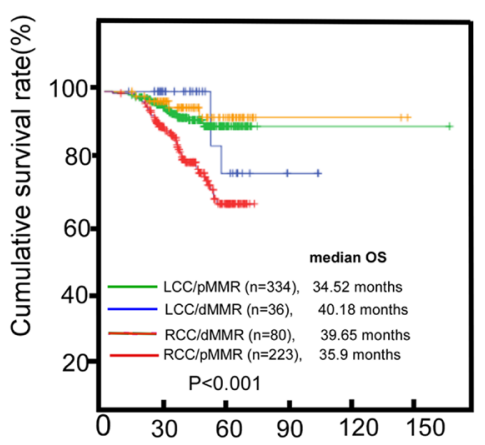

The OS difference in the four subgroups in C the cohort without chemotherapy

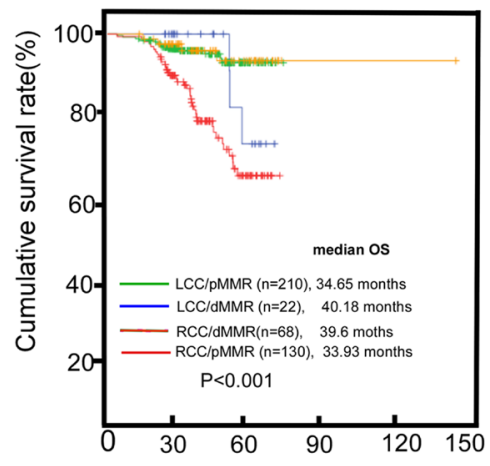

The OS difference in the four subgroups in E the cohort with chemotherapy

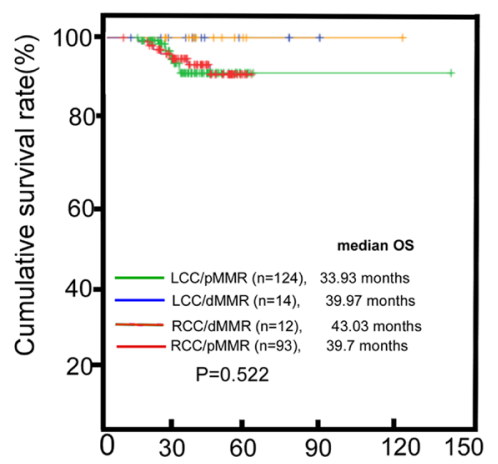

the predictor value of this parameter was not fully investigated in the early stages of disease. We found that the chemotherapy survival benefit was confined only to those with RCC, which differs from studies using targeted agents. The causes for this are unclear but may be due partly to the good response in the MSI tumor subgroup, comprising $20 \%$ of cases at this site [17, 33-36]. In addition, more men tend to have distributed cancer in the left hand side [37], LCCs are more common in highincidence regions [38], and geographical and sex-related
B The DFS difference in the four subgroups

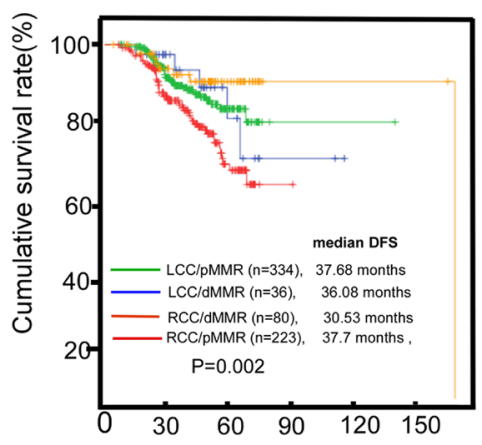

The DFS difference in the four subgroups in

D the cohort without chemotherapy

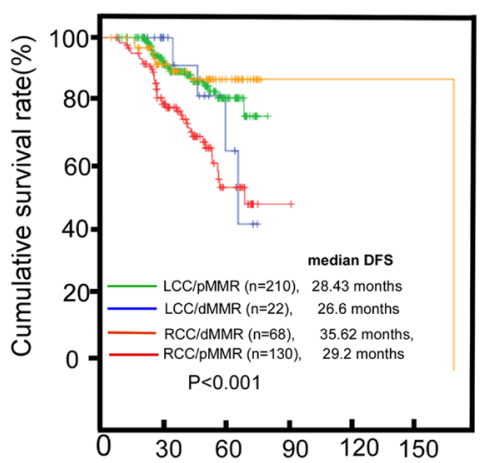

The DFS difference in the four subgroups in

\section{$\mathbf{F}$} the cohort with chemotherapy

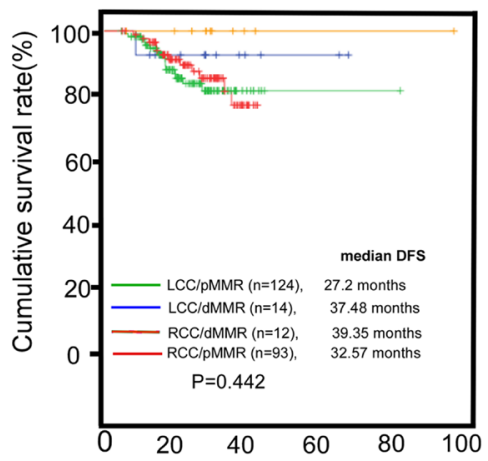

Figure 4: The survival (OS, overall survival; DFS, disease-free survival) difference between the four subgroups (RCC/pMMR, right-sided colon cancer/mismatch-repair proficient, RCC/dMMR, right-sided colon cancer/mismatch-repair deficient, LCC/dMMR, left-sided colon cancer/mismatch-repair deficient, LCC/pMMR, left-sided colon cancer/ mismatch-repair proficient) in the whole cohort (A, B), the cohort without chemotherapy $(\mathbf{C}, \mathbf{D})$ or the cohort without chemotherapy $(\mathbf{E}, \mathbf{F})$. 

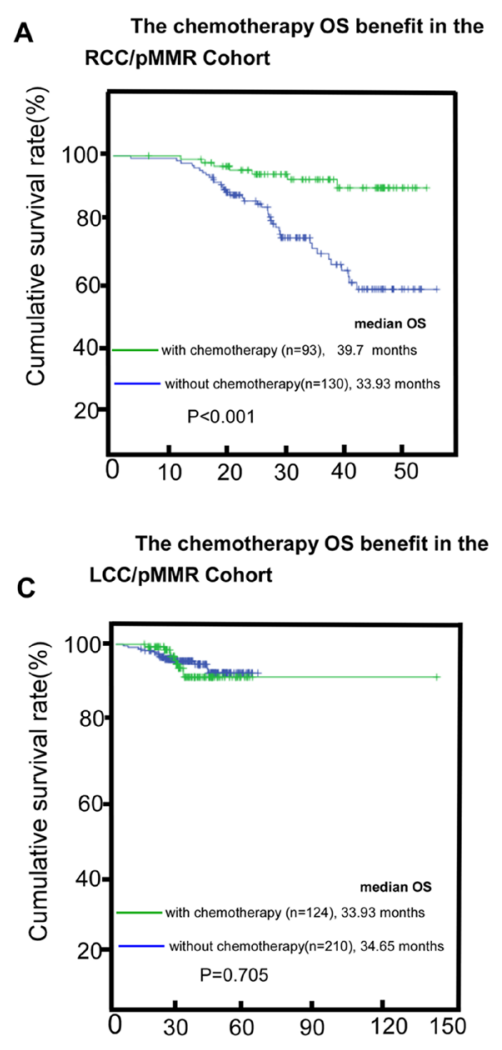

E
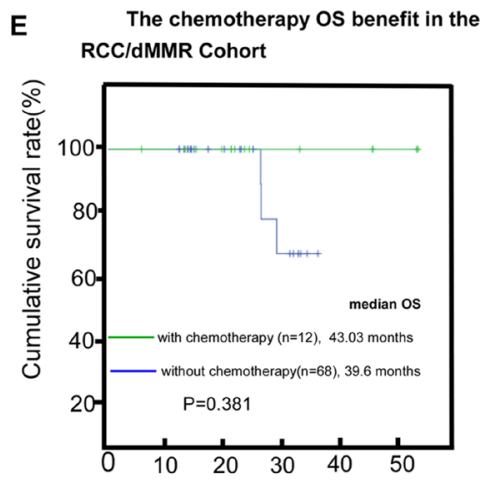

The chemotherapy OS benefit in the

\section{G} LCC/dMMR Cohort

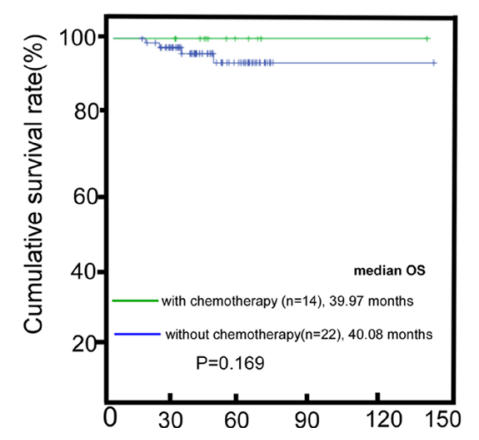
The chemotherapy DFS benefit in the
RCC/pMMR Cohort

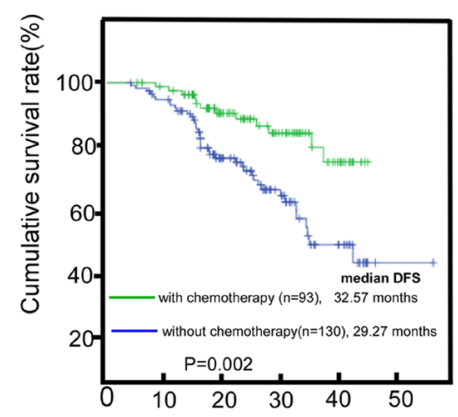

The chemotherapy DFS benefit in the

D LCC/pMMR Cohort

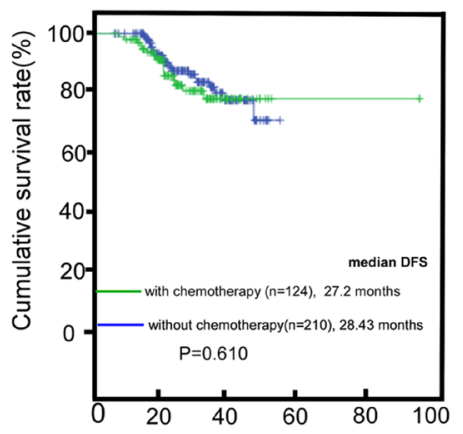
F The chemotherapy DFS benefit in the RCC/dMMR Cohort

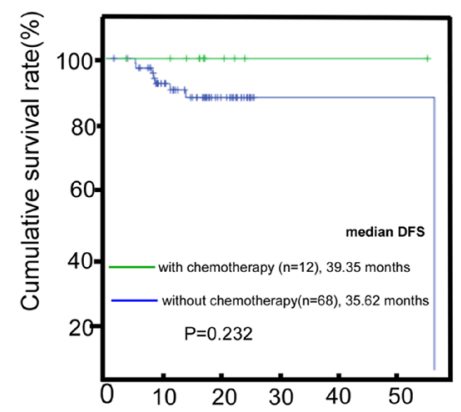

The chemotherapy DFS benefit in the H LCC/dMMR Cohort

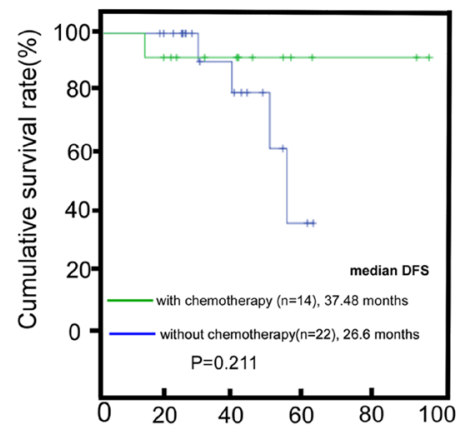

Figure 5: The adjuvant-chemotherapy survival (OS, overall survival, DFS, disease-free survival) benefit in the four subgroups (RCC/ pMMR, right-sided colon cancer/ mismatch-repair proficient (A, B), LCC/pMMR, left-sided colon cancer/ mismatch-repair proficient (C, D), RCC/dMMR, right-sided colon cancer/ mismatch-repair deficient (E, F), LCC/dMMR, left-sided colon cancer/ mismatch-repair deficient $(\mathbf{G}, \mathbf{H})$. 
differences in the incidence of colorectal cancer may be attributable to dietary and hormonal or reproductive factors, respectively. Randomized trials have also shown survival benefits from chemotherapy in rectal cancer [39].

Current opinion on the benefits of adjuvant chemotherapy for stage II tumors is divided [40, 41]. Although risk factors can indicate success of adjuvant chemotherapy in stage II disease, many questions persist e.g. is the weight of each risk factor equal? Furthermore, what is the different impact on survival time or chemotherapy benefit when patients have one or more risk factor? Such considerations have not been fully implemented in clinical practice, where many patients without risk factors received chemotherapy and vice versa. The most commonly held belief is that dMMR/ MSI-H is a predictor of decreased benefit from adjuvant chemotherapy when a fluoropyrimidine is used alone in patients with stage II disease. However, in some studies
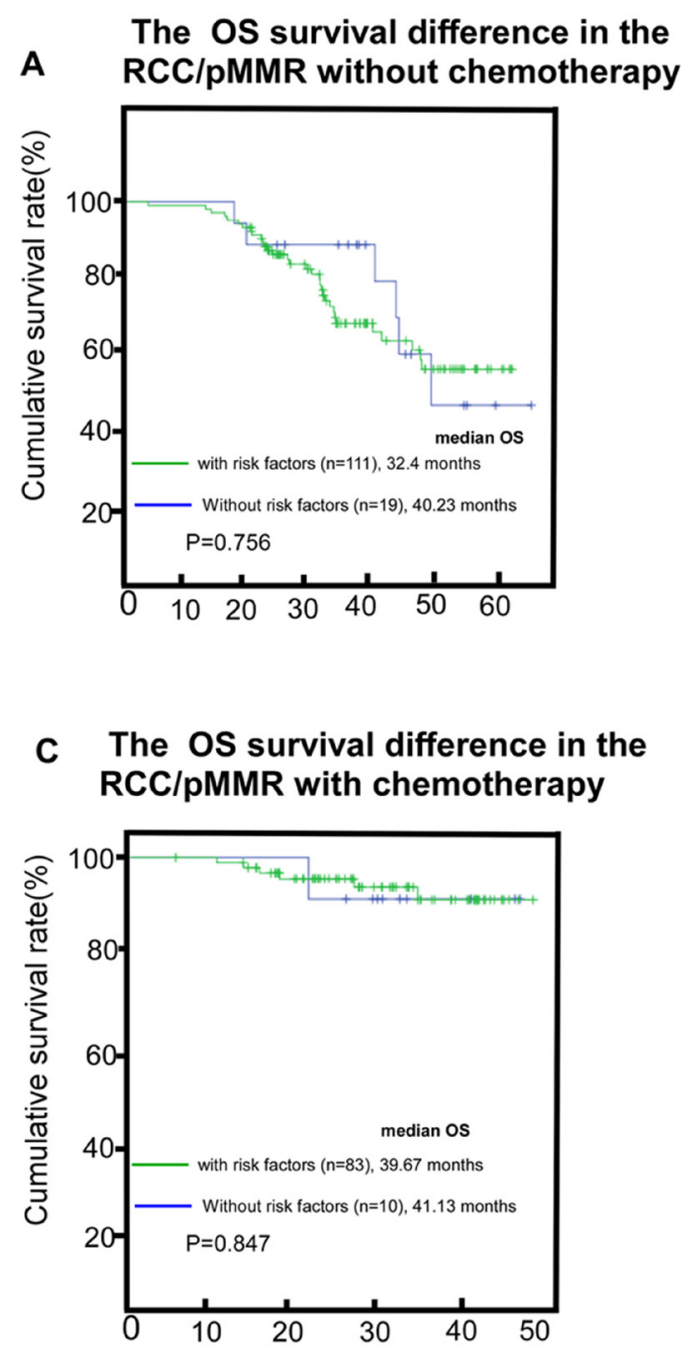

the data do not agree [4]. Therefore, the primary tumor location will be a powerful addition to MMR status and risk factors, and provide a better indication of which patients should be selected for adjuvant chemotherapy.

Neither clinically precise guidance nor practicability of adjuvant chemotherapy is guaranteed if the MMR status, risk factors, and primary tumor location are not considered together. Therefore, a combination of the two methods is needed. In the non-chemotherapy cohort, the combination of pMMR and RCC, the two subgroups with poor prognosis respectively, had the poorest prognosis. Interesting, only this group attained benefit from chemotherapy. At the same time, we found that for patients who received chemotherapy, both the chemotherapy regimens and number of risk factors were similar across all the four groups. $\mathrm{Li}$ [42] found that the combination of MMR status and tumor location helped to stratify CRC patients, where RCC patients with dMMR had a higher OS

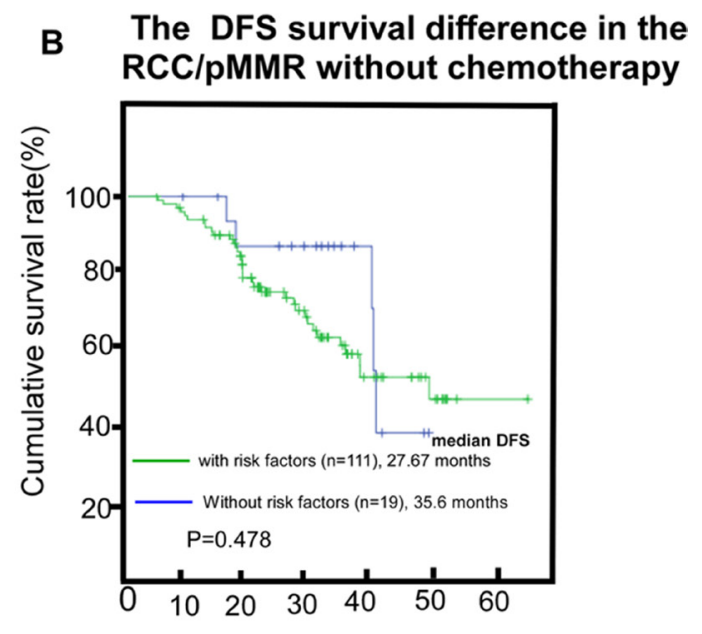

\section{The DFS survival difference in the RCC/pMMR with chemotherapy}

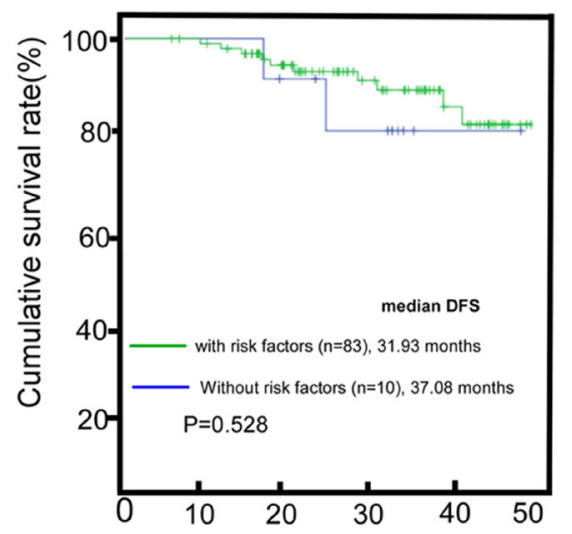

Figure 6: The survival difference between the subgroups with the risk-factors and the subgroups without risk-factors in the RCC/pMMR cohort without adjuvant-chemotherapy, (A and B) the survival difference between the subgroups with the risk-factors and the subgroups without risk-factors in the RCC/pMMR cohort with adjuvant-chemotherapy, $(\mathbf{C}$ and $\mathbf{D})$ risk factors include one of the following factors: perforated cancer, pT4N0 with vascular emboli, vascular invasion and/or obstructive colorectal tumor; RCC/pMMR, right-sided colon cancer/ mismatch-repair proficient. 
than those with pMMR, as was similarly observed in LCC patients. In contrast, rectal cancer patients with dMMR had a lower OS than those with pMMR. However, this study did not investigate the use of chemotherapy.

Our findings require further investigation and validation since this was a retrospective study. The effects of treatments after relapse or metastasis, which inevitably impact upon OS, were unclear. However, we believe it is welcoming that the DFS in most conditions also showed significant accordance with OS. The judgment of MMR status depended only on the immunohistochemistry results and did not distinguish between the deficiency subtypes. Therefore, it was not possible to accurately determine MSS, MSI-low, and MSI-H. Fortunately, MMR status has been shown to be highly consistent with MSI status [43]. Finally, one other limitation of this study was the small number of patients, especially the dMMR subgroup. All of these limitations need to be overcome in future studies.

In summary, for the first time we have demonstrated that when combined with MMR status, the primary tumor location provides superiority in patient selection for $\mathrm{pMMR} / \mathrm{RCC}$ patients who require adjuvant chemotherapy. This has implications for risk factors recommended by the NCCN guideline in assisting the selection of adjuvant chemotherapy for CRC patients with stage II disease.

\section{Ethics approval and consent to participate}

Ethical approval was obtained from the respective institutional review boards of the Ethics Committee of Sun Yat-sen University Cancer Center. All patients provided written informed consent to participate in this study.

\section{Consent for publication}

Not applicable.

\section{Avaliability of data and material}

Raw data was deposited in the Research Data Deposit system (research data deposit number RDDA2017000269, http://www.researchdata.org.cn) of Sun Yat-sen University Cancer and can be obtained from the corresponding authors on reasonable request.

\section{Abbreviations}

MMR (mismatch repair); LCC (left-sided colon cancer); RCC (right-sided colon cancer); OS (overall survival); DFS (Disease-free survival); DMMR (mismatch repair-deficient); MMR (mismatch repair-proficient); NCCN, (National Comprehensive Cancer Network); LV, (leucovorin); 5-FU/LV, (5-Fluorouracil/Leucovorin); FOLFOX, (5-Fluorouracil+oxaliplatin+Leucovorin); CapeOX, (Oxaliplatin+ Capecitabine); FLOX, (5-Fluoro
uracil+oxaliplatin+Leucovorin); IFL, (irinoteca; mCRC, (metastatic colorectal cancer); ALB, (albumin); TLN, (Total lymph node).

\section{Author contributions}

YL, ZB and XLP designed the overall project. YL analyzed the data and wrote the manuscript; HWZ and KPF collected and analyzed the data; JC and YQ performed the research; YL did the statistical analysis. All the authors (YL, HWZ, YQ, KPF, XQK, JC, ZB, XLP) have read and approved the final manuscript.

\section{ACKNOWLEDGMENTS}

Thanks to the native English speaker of Elixigen Company (Huntington Beach, California) for revising our manuscript.

\section{CONFLICTS OF INTEREST}

No individual person's data in any form were involved in this study.

\section{FUNDING}

The authors received no specific funding for this work. The funding agency had no role in the study design, data collection and analysis, decision to publish, or preparation of the manuscript.

\section{REFERENCES}

1. Boland GM, Chang GJ, Haynes AB, Chiang YJ, Chagpar R, Xing Y, Hu CY, Feig BW, You YN, Cormier JN. Association between adherence to National Comprehensive Cancer Network treatment guidelines and improved survival in patients with colon cancer. Cancer. 2013; 119:1593-1601.

2. Chen G. [Interpretation of the updates of NCCN 2017 version 1.0 guideline for colorectal cancer]. [Article in Chinese]. Zhonghua Wei Chang Wai Ke Za Zhi. 2017; 20:28-33.

3. Ribic CM, Sargent DJ, Moore MJ, Thibodeau SN, French AJ, Goldberg RM, Hamilton SR, Laurent-Puig P, Gryfe R, Shepherd LE, Tu D, Redston M, Gallinger S. Tumor microsatellite-instability status as a predictor of benefit from fluorouracil-based adjuvant chemotherapy for colon cancer. N Engl J Med. 2003; 349:247-257.

4. Sargent DJ, Marsoni S, Monges G, Thibodeau SN, Labianca R, Hamilton SR, French AJ, Kabat B, Foster NR, Torri V, Ribic C, Grothey A, Moore M, et al. Defective mismatch repair as a predictive marker for lack of efficacy of fluorouracil-based adjuvant therapy in colon cancer. J Clin Oncol. 2010; 28:3219-3226. 
5. Hutchins G, Southward K, Handley K, Magill L, Beaumont C, Stahlschmidt J, Richman S, Chambers P, Seymour M, Kerr D, Gray R, Quirke P. Value of mismatch repair, KRAS, and BRAF mutations in predicting recurrence and benefits from chemotherapy in colorectal cancer. J Clin Oncol. 2011; 29:1261-1270.

6. Bertagnolli MM, Redston M, Compton CC, Niedzwiecki D, Mayer RJ, Goldberg RM, Colacchio TA, Saltz LB, Warren RS. Microsatellite instability and loss of heterozygosity at chromosomal location 18q: prospective evaluation of biomarkers for stages II and III colon cancer--a study of CALGB 9581 and 89803. J Clin Oncol. 2011; 29:31533162.

7. Gray RG, Quirke P, Handley K, Lopatin M, Magill L, Baehner FL, Beaumont C, Clark-Langone KM, Yoshizawa CN, Lee M, Watson D, Shak S, Kerr DJ. Validation study of a quantitative multigene reverse transcriptase-polymerase chain reaction assay for assessment of recurrence risk in patients with stage II colon cancer. J Clin Oncol. 2011; 29:4611-4619.

8. Salazar R, Roepman P, Capella G, Moreno V, Simon I, Dreezen C, Lopez-Doriga A, Santos C, Marijnen C, Westerga J, Bruin S, Kerr D, Kuppen P, et al. Gene expression signature to improve prognosis prediction of stage II and III colorectal cancer. J Clin Oncol. 2011; 29:17-24.

9. Bufill JA. Colorectal cancer: evidence for distinct genetic categories based on proximal or distal tumor location. Annals of internal medicine. 1990; 113:779-788.

10. Missiaglia E, Jacobs B, D'Ario G, Di Narzo AF, Soneson C, Budinska E, Popovici V, Vecchione L, Gerster S, Yan $\mathrm{P}$, Roth AD, Klingbiel D, Bosman FT, et al. Distal and proximal colon cancers differ in terms of molecular, pathological, and clinical features. Ann Oncol. 2014; 25:1995-2001.

11. Guinney J, Dienstmann R, Wang X, de Reynies A, Schlicker A, Soneson C, Marisa L, Roepman P, Nyamundanda G, Angelino P, Bot BM, Morris JS, Simon IM, et al. The consensus molecular subtypes of colorectal cancer. Nature Medicine. 2015; 21:1350-1356.

12. Arnold D, Lueza B, Douillard JY, Peeters M, Lenz HJ, Venook A, Heinemann V, Van Cutsem E, Pignon JP, Tabernero J, Cervantes A, Ciardiello F. Prognostic and predictive value of primary tumour side in patients with RAS wild-type metastatic colorectal cancer treated with chemotherapy and EGFR directed antibodies in six randomised trials. Annals of oncology. 2017; 28:1713-1729.

13. Holch JW, Ricard I, Stintzing S, Modest DP, Heinemann V. The relevance of primary tumour location in patients with metastatic colorectal cancer: A meta-analysis of first-line clinical trials. Eur J Cancer. 2017; 70:87-98.

14. Arnold D, Lueza B, Douillard JY, Peeters M, Lenz HJ, Venook A, Heinemann V, Van Cutsem E, Pignon JP, Tabernero J, Cervantes A, Ciardiello F. Prognostic and predictive value of primary tumour side in patients with RAS wild-type metastatic colorectal cancer treated with chemotherapy and EGFR directed antibodies in six randomized trials. Annals of oncology. 2017; 28:17131729.

15. Gill S, Loprinzi CL, Sargent DJ, Thome SD, Alberts SR, Haller DG, Benedetti J, Francini G, Shepherd LE, Francois Seitz J, Labianca R, Chen W, Cha SS, et al. Pooled analysis of fluorouracil-based adjuvant therapy for stage II and III colon cancer: who benefits and by how much? J Clin Oncol. 2004; 22:1797-1806.

16. Yamauchi M, Lochhead P, Morikawa T, Huttenhower C, Chan AT, Giovannucci E, Fuchs C, Ogino S. Colorectal cancer: a tale of two sides or a continuum? Gut. 2012; 61:794-797.

17. Gervaz P, Bucher P, Morel P. Two colons-two cancers: paradigm shift and clinical implications. Journal of surgical oncology. 2004; 88:261-266.

18. Distler P, Holt PR. Are right- and left-sided colon neoplasms distinct tumors? Digestive diseases (Basel, Switzerland). 1997; 15:302-311.

19. Gonzalez EC, Roetzheim RG, Ferrante JM, Campbell R. Predictors of proximal vs. distal colorectal cancers. Diseases of the colon and rectum. 2001; 44:251-258.

20. McCashland TM, Brand R, Lyden E, de Garmo P. Gender differences in colorectal polyps and tumors. The American journal of gastroenterology. 2001; 96:882-886.

21. Au AE, Sashindranath M, Borg RJ, Kleifeld O, Andrews RK, Gardiner EE, Medcalf RL, Samson AL. Activated platelets rescue apoptotic cells via paracrine activation of EGFR and DNA-dependent protein kinase. Cell death \& disease. 2014; 5:e1410.

22. Aleksandrova K, Jenab M, Boeing H, Jansen E, Buenode-Mesquita HB, Rinaldi S, Riboli E, Overvad K, Dahm $\mathrm{CC}$, Olsen A, Tjonneland A, Boutron-Ruault MC, Clavel-Chapelon F, et al. Circulating C-reactive protein concentrations and risks of colon and rectal cancer: a nested case-control study within the European Prospective Investigation into Cancer and Nutrition. American journal of epidemiology. 2010; 172:407-418.

23. Boeckx N, Koukakis R, Op de Beeck K, Rolfo C, Van Camp G, Siena S, Tabernero J, Douillard JY, Andre T, Peeters M. Primary tumor sidedness has an impact on prognosis and treatment outcome in metastatic colorectal cancer: results from two randomized first-line panitumumab studies. Ann Oncol. 2017; 28:1862-1868.

24. Brungs D, Aghmesheh M, de Souza P, Ng W, Chua W, Carolan M, Clingan P, Healey E, Rose J, Tubaro T, Ranson M. Sidedness is prognostic in locoregional colon cancer: an analysis of 9509 Australian patients. BMC Cancer. 2017; 17:251.

25. He WZ, Liao FX, Jiang C, Kong PF, Yin CX, Yang Q, Qiu HJ, Zhang B, Xia LP. Primary Tumor Location as a Predictive Factor for First-line Bevacizumab Effectiveness 
in Metastatic Colorectal Cancer Patients. J Cancer. 2017; 8:388-394.

26. Rohr UP, Herrmann P, Ilm K, Zhang H, Lohmann S, Reiser A, Muranyi A, Smith J, Burock S, Osterland M, Leith K, Singh S, Brunhoeber P, et al. Prognostic value of MACC1 and proficient mismatch repair status for recurrence risk prediction in stage II colon cancer patients: the BIOGRID studies. Ann Oncol. 2017; 28:1869-1875.

27. Andre T, de Gramont A, Vernerey D, Chibaudel B, Bonnetain F, Tijeras-Raballand A, Scriva A, Hickish T, Tabernero J, Van Laethem JL, Banzi M, Maartense E, Shmueli E, et al. Adjuvant Fluorouracil, Leucovorin, and Oxaliplatin in Stage II to III Colon Cancer: Updated 10Year Survival and Outcomes According to BRAF Mutation and Mismatch Repair Status of the MOSAIC Study. J Clin Oncol. 2015; 33:4176-4187.

28. Wang F, Bai L, Liu TS, Yu YY, He MM, Liu KY, Luo HY, Zhang DS, Jin Y, Wang FH, Wang ZQ, Wang DS, Qiu MZ, et al. Right-sided colon cancer and left-sided colorectal cancers respond differently to cetuximab. Chinese journal of cancer. 2015; 34:384-393.

29. Lu HJ, Lin JK, Chen WS, Jiang JK, Yang SH, Lan YT, Lin CC, Chang SC, Teng HW. Primary tumor location is an important predictive factor for wild-type KRAS metastatic colon cancer treated with cetuximab as front-line biotherapy. Asia-Pacific journal of clinical oncology. 2016; 12:207-215.

30. Brule SY, Jonker DJ, Karapetis CS, O'Callaghan CJ, Moore MJ, Wong R, Tebbutt NC, Underhill C, Yip D, Zalcberg JR, Tu D, Goodwin RA. Location of colon cancer (right-sided versus left-sided) as a prognostic factor and a predictor of benefit from cetuximab in NCIC CO.17. European journal of cancer (Oxford, England : 1990). 2015; 51:1405-1414.

31. Boisen MK, Johansen JS, Dehlendorff C, Larsen JS, Osterlind K, Hansen J, Nielsen SE, Pfeiffer P, Tarpgaard LS, Hollander NH, Keldsen N, Hansen TF, Jensen BB, Jensen BV. Primary tumor location and bevacizumab effectiveness in patients with metastatic colorectal cancer. Ann Oncol. 2013; 24:2554-2559.

32. Wong HL, Lee B, Field K, Lomax A, Tacey M, Shapiro J, McKendrick J, Zimet A, Yip D, Nott L, Jennens R, Richardson G, Tie J, et al. Impact of Primary Tumor Site on Bevacizumab Efficacy in Metastatic Colorectal Cancer. Clinical colorectal cancer. 2016; 15:e9-e15.

33. Thibodeau SN, Bren G, Schaid D. Microsatellite instability in cancer of the proximal colon. Science. 1993; 260:816819.
34. Popat S, Hubner R, Houlston RS. Systematic review of microsatellite instability and colorectal cancer prognosis. J Clin Oncol. 2005; 23:609-618.

35. Poynter JN, Siegmund KD, Weisenberger DJ, Long TI, Thibodeau SN, Lindor N, Young J, Jenkins MA, Hopper JL, Baron JA, Buchanan D, Casey G, Levine AJ, et al. Molecular characterization of MSI-H colorectal cancer by MLHI promoter methylation, immunohistochemistry, and mismatch repair germline mutation screening. Cancer epidemiology, biomarkers \& prevention. 2008; 17:32083215 .

36. Kim H, Jen J, Vogelstein B, Hamilton SR. Clinical and pathological characteristics of sporadic colorectal carcinomas with DNA replication errors in microsatellite sequences. The American journal of pathology. 1994; 145:148-156.

37. Jass JR. Subsite distribution and incidence of colorectal cancer in New Zealand, 1974-1983. Diseases of the colon and rectum. 1991; 34:56-59.

38. Wheeler JM, Bodmer WF, Mortensen NJ. DNA mismatch repair genes and colorectal cancer. Gut. 2000; 47:148-153.

39. Thomas PR, Lindblad AS. Adjuvant postoperative radiotherapy and chemotherapy in rectal carcinoma: a review of the Gastrointestinal Tumor Study Group experience. Radiotherapy and oncology. 1988; 13:245-252.

40. Verhoeff SR, van Erning FN, Lemmens VE, de Wilt JH, Pruijt JF. Adjuvant chemotherapy is not associated with improved survival for all high-risk factors in stage II colon cancer. International journal of cancer. 2016; 139:187-193.

41. Kim JE, Hong YS, Kim HJ, Kim KP, Lee JL, Park SJ, Lim SB, Park IJ, Kim CW, Yoon YS, Yu CS, Kim JC, Hoon KJ, Kim TW. Defective Mismatch Repair Status was not Associated with DFS and OS in Stage II Colon Cancer Treated with Adjuvant Chemotherapy. Annals of surgical oncology. 2015; 22:S630-637.

42. Li C, Xu Q, Chen L, Luo C, Ying J, Liu J. C-reactive protein (CRP) as a prognostic factor for colorectal cancer after surgical resection of pulmonary metastases. Bulletin du cancer. 2017; 104:232-236.

43. Yan WY, Hu J, Xie L, Cheng L, Yang M, Li L, Shi J, Liu BR, Qian XP. Prediction of biological behavior and prognosis of colorectal cancer patients by tumor MSI/ MMR in the Chinese population. Onco Targets Ther. 2016; 9:7415-7424. 